\title{
Analisis Biaya dan Manfaat Pembangkit Listrik Tenaga Listrik (PLTS) pada Kabupaten Muara Enim
}

\author{
Gusti Prasetyo Rendy Anggara, Jaka Windarta \\ Magister Energi, Sekolah Pascasarjana, Universitas Diponegoro; \\ Email : gusti@students.undip.ac.id (G.P.R.A); jakawindarta@lecturer.undip.ac.id (J.W);
}

\begin{abstract}
Abstrak : Kabupaten Muara Enim merupakan daerah agraris dengan luas wilayah 7.483,06 Km², terbagi menjadi 22 kecamatan, terdiri dari 245 desa definitif dan 10 kelurahan. Penggunaan listrik di Kabupaten Muara Enim tahun 2020 dilihat dari jumlah pelanggan, mengalami peningkatan dibandingkan dengan tahun 2019. Dari 77.187 pelanggan menjadi 81.183 pelanggan, atau naik sekitar 5,18 persen. Kebutuhan pembangunan pembangkit memerlukan beberapa pertimbangan terkait sumber energi yang akan digunakan. Pusat Teknologi Pengembangan Sumber Daya Energi (PTPSE) pada tahun 2015 melalui outlook energi Indonesia memperkirakan harga minyak akan meningkat menjadi sebesar US\$188,9 per barel pada tahun 2050, harga batubara menjadi US\$210,7 per ton pada tahun 2050 dan harga LNG akan meningkat menjadi US\$210,7 per MMBTU pada tahun 2050. Kenaikan harga tersebut diproyeksikan akan membebani anggaran pemerintah. Oleh karena itu perlunya sebuah energi alternatif yang dapat menjadi sebuah solusi terutama di kabupaten Muara Enim. Dalam kajian ini didapati bahwa proyek akan layak jika tariff PLTS minimal sebesar $28 \%$ beserta biaya operasionalnya dibawah $35 \% /$ tahun
\end{abstract}

Kata Kunci : PLTS, Analisis Biaya, Muara Enim

\section{Pendahuluan}

Kabupaten Muara Enim merupakan daerah agraris dengan luas wilayah 7.483,06 Km², terbagi menjadi 22 kecamatan, terdiri dari 245 desa definitif dan 10 kelurahan. Batas-batas wilayah Muara Enim mulai tahun 2013 antara lain: Sebelah Utara dengan Kota Palembang, Kabupaten Musi Banyuasin dan Penukal Abab Lematang Ilir; Sebelah Selatan dengan Kabupaten Ogan Komering Ulu dan Ogan Komering Ulu Selatan; Sebelah Timur dengan Kabupaten Ogan Ilir, Kabupaten Ogan Komering Ilir dan Kota Prabumulih; Sebelah Barat dengan Kabupaten Musi Rawas dan Kabupaten Lahat.

Listrik merupakan salah satu komponen vital dalam kehidupan masyarakat. Penggunaan listrik di Kabupaten Muara Enim tahun 2020 dilihat dari jumlah pelanggan, mengalami peningkatan dibandingkan dengan tahun 2019. Dari 77.187 pelanggan menjadi 81.183 pelanggan, atau naik sekitar 5,18 persen. PT.Bukit Asam sebagai salah satu perusahaan BUMN yang bergerak di tambang batubara berencana membangun PLTS di kawasan bekas galian tambang yang ada di Kabupaten Muara Enim sebagai salah satu bentuk konservasi lingkungan dan juga ikut berperan serta dalam mengatasi krisis kelistrikan di Indonesia. 
Vol. 1, No. 2, pp $78-85$

doi: $10.14710 /$ jebt.2020.11433

Kebutuhan pembangunan pembangkit memerlukan beberapa pertimbangan terkait sumber energi yang akan digunakan. Pusat Teknologi Pengembangan Sumber Daya Energi (PTPSE) pada tahun 2015 melalui outlook energi Indonesia memperkirakan harga minyak akan meningkat menjadi sebesar US $\$ 188,9$ per barel pada tahun 2050, harga batubara menjadi US $\$ 210,7$ per ton pada tahun 2050 dan harga LNG akan meningkat menjadi US\$210,7 per MMBTU pada tahun 2050. Kenaikan harga tersebut diproyeksikan akan membebani anggaran pemerintah. Kenaikan harga minyak, batubara dan LNG terlihat pada Tabel 1.

Tabel 1.

Kenaikan Harga Minyak, Batubara dan LNG (Outlook Energi Indonesia, 2019)

\begin{tabular}{llccccc}
\hline \multirow{2}{*}{ Keterangan } & \multirow{2}{*}{ Satuan } & \multicolumn{5}{c}{ Tahun } \\
\cline { 3 - 6 } & Juta & 2013 & 2016 & 2020 & 2025 & 2050 \\
\hline Populasi & \%/Tahun & 1,4 & 1,2 & 1,2 & 1,0 & 0,4 \\
Pertumbahan Rata - Rata & USD/Barrel & 108,6 & 71,1 & 79,1 & 91,1 & 188,9 \\
Harga Minyak (Brent Price) & USD/Ton & 84,6 & 69,7 & 81,9 & 98,1 & 210,7 \\
Harga Batubara (Australian Coal) & USD/MMBTU & 17,3 & 16,3 & 16,6 & 18,2 & 29,0 \\
Harga LNG (CIF on Japan) & Triliun Rupiah & & & & & \\
PDB & Tahun 2010 & 7.955 & 9.272 & 12.266 & 17.952 & 94.205 \\
& Nilai Sekarang & 9.087 & 13.026 & 20.771 & 30.472 & 128.879 \\
Pertumbuhan PDB & \%/Tahun & 5,21 & 5,70 & 8,00 & 7,79 & 6,00 \\
\hline
\end{tabular}

Permasalahan lain yaitu penggunaan batubara, LNG dan bahan lainnya akan meningkatkan $\mathrm{CO}_{2}$ di Indonesia. Emisi $\mathrm{CO}_{2}$ se-Indonesia akan meningkat 2 kali lipat dari 201 juta ton pada tahun 2015 menjadi 383 juta ton tahun 2024. Dari 383 juta ton emisi tersebut, 333 juta ton (87\%) berasal dari pembakaran batubara. Hal ini ditunjukkan pada Gambar 1.

\section{Emisi Gas Rumah Kaca}

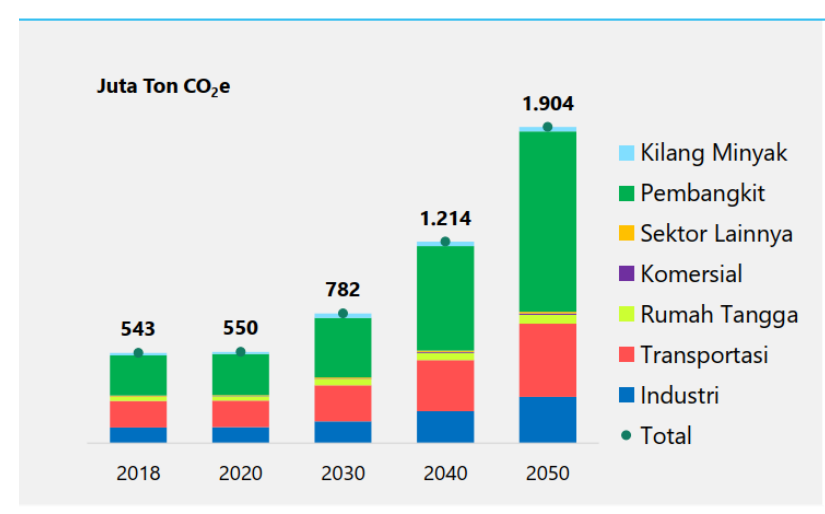

Peningkatan pemanfaatan energi terbarukan belum mampu menurunkan emisi GRK per kapita nasional, bahkan cenderung meningkat dari 2,1 ton $\mathrm{CO}_{2} \mathrm{e}$ /kapita pada tahun 2018 menjadi 5,9 ton $\mathrm{CO}_{2} \mathrm{e} /$ kapita pada tahun 2050. Di sisi lain, peningkatan bauran energi terbarukan mampu memenuhi kriteria pembangunan nasional yang rendah karbon. Intensitas emisi $\mathrm{CO}_{2} \mathrm{e}$ per GDP mengalami penurunan yang cukup signifikan dari 52,1 ton $\mathrm{CO}_{2} \mathrm{e} /$ miliar Rupiah menjadi 37,7 ton $\mathrm{CO}$, e/miliar Rupiah pada tahun 2050.

Emisi GRK pada tahun 2050 diperkirakan sebesar 1.904 juta ton $\mathrm{CO}_{2}$ e. Sektor pembangkit listrik merupakan penyumbang emisi GRK terbesar karena kebutuhan listrik yang meningkat lebih pesat dari pada jenis energi final lainnya dan penggunaan bahan bakar batubara masih dominan dibanding dengan pengunaan energi fosil lainnya. Sektor penyumbang emisi terbesar selanjutnya adalah sektor transportasi sebagai akibat dari penggunaan BBM yang masih tinggi hingga 2050.

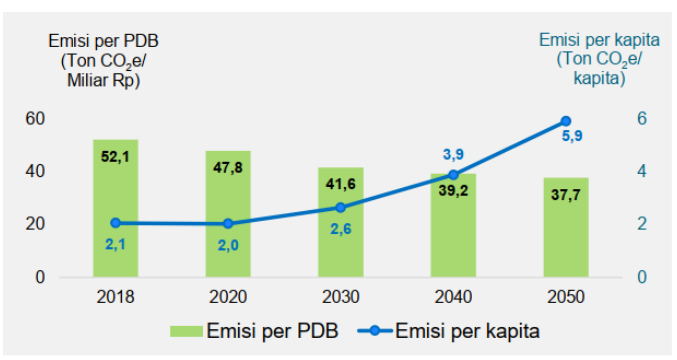

Gambar 2. Pertumbuhan Emisi Gas Rumah Kaca (Outlook Energi Indonesia 2020 - BPPT) 
Vol. 1, No. 2, pp $78-85$

doi: $10.14710 /$ jebt.2020.11433

Harga minyak, batubara dan LNG yang diproyeksikan semakin tinggi dan semakin meningkatnya emisi $\mathrm{CO}_{2}$ mendorong pemenuhan kebutuhan listrik pada Kabupaten Muara Enim melalui pembangunan Pembangkit Listrik Tenaga Surya (PLTS). Hal ini juga didukung dengan adanya potensi energi baru dan terbarukan melalui tenaga surya yang menghasilkan daya sebesar 4,80 kWh/m²/hari (Kementerian ESDM, 2015).

\section{Metodologi}

Data yang digunakan dalam penelitian ini didapatkan melalui penbelajaran literature-literatur yang terkait dengan topik penelitian. Dalam penelitian ini akan digunakan analisis biaya manfaat untuk mengevaluasi penggunaan sumber-sumber ekonomi agar sumber yang langka tersebut dapat digunakan secara efisien. Adapun tahapan penelitian ini dapat dilihat pada Gambar 2.

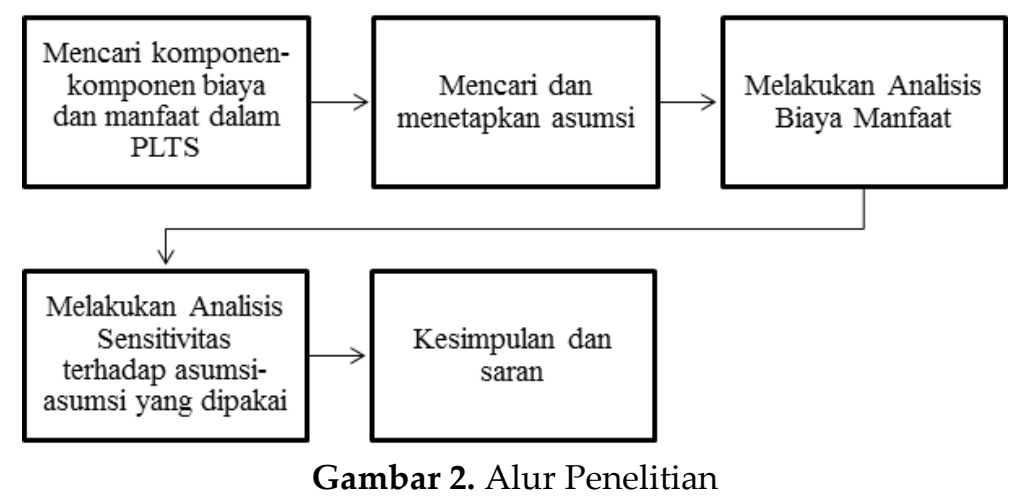

\section{Pembahasan}

Pembangunan PLTS pada Kabupaten Muara Enim dilaksanakan dengan pembiayaan oleh BUMN / Pihak Swasta. Pembangunan PLTS dengan kapasitas sebesar 20-100 MW, suku bunga diperkirakan sebesar 13,5\% (berdasarkan suku bank yang berlaku) dan masa operasional PLTS selama 25 tahun. Biaya dan manfat serta asumsi yang digunakan dalam perhitungan biaya dan manfaat pembangunan PLTS pada Kabupaten Muara Enim sebagai berikut.

1) Asumsi atas Biaya

Biaya yang dimasukkan sebagai komponen dalam perhitungan biaya dan manfat yaitu biaya/investasi untuk pembangunan PLTS dan biaya operasional untuk menjalankan PLTS. Biaya/investasi pembangunan PLTS terdiri dari biaya pemerolehan tanah, bangunan pembangunan PLTS, baterei dan konsultan. Biaya pembangunan PLTS yaitu sebesar USD $\$ 1,77 /$ watt. Rincian biaya pembangunan seperti diuraikan pada gambar 3. Biaya operasional terdiri dari biaya pemeliharaan, biaya penggantian baterei dan gaji. Rincian biaya untuk pembangunan PLTS pada Kabupaten Muara Enim ditunjukkan pada Tabel 2. 
Vol. 1, No. 2, pp $78-85$

doi: $10.14710 /$ jebt.2020.11433

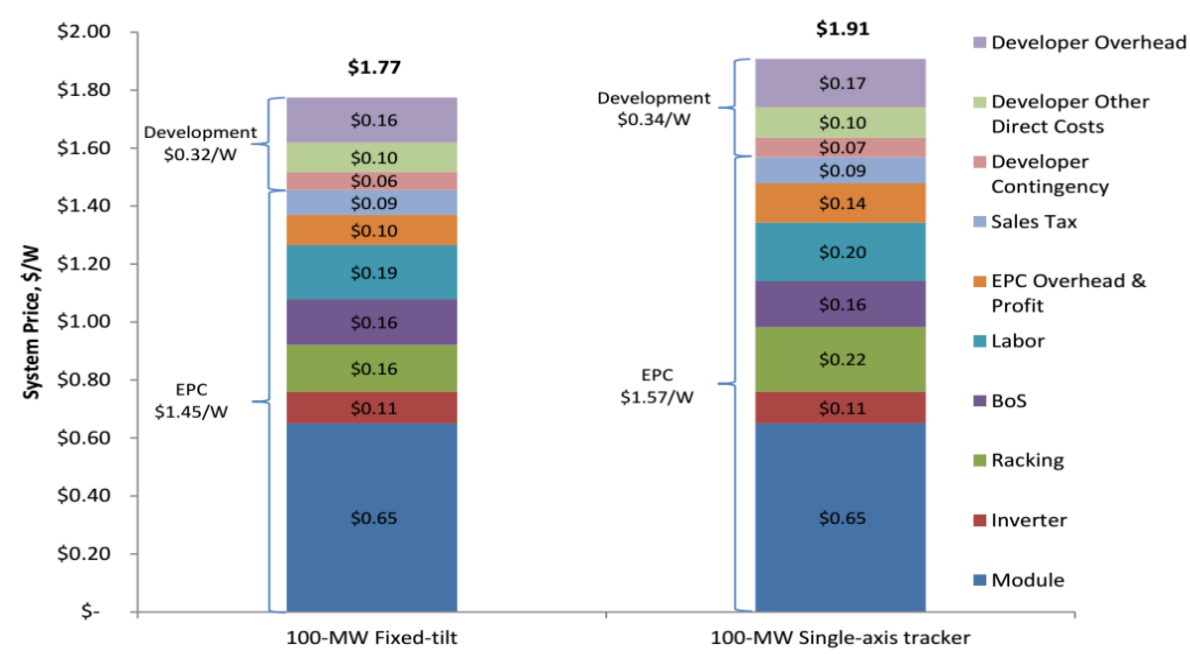

Gambar 3. Asumsi Biaya untuk Pembangunan PLTS (U.S. Photovoltaic Prices and Cost Breakdowns: Q1 2015 Benchmarks for Residential, Commercial, and Utility-Scale Systems)

Tabel 2.

Rincian Biaya untuk Pembangunan PLTS pada Kabupaten Muara Enim

\begin{tabular}{|c|c|c|}
\hline No. & Uraian & Asumsi \\
\hline \multicolumn{3}{|c|}{ A. Biaya Pembangunan PLTS } \\
\hline & Tanah & Tanah yang dibutuhkan 100 m² dengan harga Rp120.000,-/m². \\
\hline 2. & Bangunan & Bangunan dengan luas $100 \mathrm{~m}^{2}$ dengan harga Rp750.000,-/m². \\
\hline 3. & Investasi/Pembangunan PLTS & - Kapasitas PLTS $=20 \mathrm{MW}$ \\
\hline & & - Biaya pembangunan USD $\$ 1,77 /$ watt \\
\hline & & - Nilai kurs USD\$1 = Rp14.300,- \\
\hline 4. & Baterai & Kapasitas baterai $100.000 \mathrm{kWh}$. \\
\hline & Konsultan & $\begin{array}{l}\text { Biaya konsultan sebesar 2,5\% dari nilai investasi keseluruhan } \\
\text { pembangunan PLTS. }\end{array}$ \\
\hline \multicolumn{3}{|c|}{ B. Biaya Operasional } \\
\hline & Biaya Pemeliharaan & $\begin{array}{l}\text { Biaya pemeliharaan per tahun ditetapkan sebesar Rp } \\
\text { 30.000.000,00. }\end{array}$ \\
\hline & Biaya Penggantian Baterei & $\begin{array}{l}\text { Kerusakan baterei sebesar } 16,67 \% \text { per tahun atau baterei diganti } \\
\text { setiap enam tahun. }\end{array}$ \\
\hline & Gaji & $\begin{array}{l}\text { - Jumlah pegawai sebanyak dua puluh orang terdiri dari } \\
\text { sepuluh engineer dan sepuluh karyawan biasa. } \\
\text { - Gaji didasarkan pada Upah Minimum Provinsi (UMP) } \\
\text { dengan rincian gaji engineer } 3 x \text { UMP dan karyawan biasa 1x } \\
\text { UMP. }\end{array}$ \\
\hline & Biaya depresiasi & $\begin{array}{l}\text { Biaya depresiasi untuk masa } 25 \text { tahun atau sebesar } 4 \% \text { per } \\
\text { tahun. }\end{array}$ \\
\hline
\end{tabular}


Vol. 1, No. 2, pp $78-85$

doi: $10.14710 /$ jebt.2020.11433

2) Asumsi atas Manfaat

Manfaat atas pembangunan PLTS pada Kabupaten Muara Enim diperoleh dari manfaat financial/keuangan berupa penjualan listrik kepada PT PLN (Persero) dan manfaat sosial berupa pengurangan emisi $\mathrm{CO}_{2}$ dengan adanya pembangunan PLTS dibandingkan dengan emisi $\mathrm{CO}_{2}$ jika pembangunan menggunakan sumber daya batubara. Rincian asumsi manfaat dari pembangunan PLTS pada Kabupaten Muara Enim ditunjukkan pada Tabel 3.

Tabel 3.

Rincian Manfaat Pembangunan PLTS pada Kabupaten Muara Enim

\begin{tabular}{|c|c|c|}
\hline No & Uraian & Asumsi \\
\hline 1. & $\begin{array}{l}\text { Penjualan listrik kepada PT PLN } \\
\text { (Persero). }\end{array}$ & $\begin{array}{ll}\text { - } & \text { Jam operasional PLTS yaitu } 10 \text { jam/hari. } \\
\text { - } & \text { Kapasitas produksi 100\% atau produksi per tahun } \\
& \text { sebesar 73.000.000 kWh. } \\
\text { - } & \text { PT PLN (Persero) membeli listrik 100\%. } \\
\text { - } & \text { Feed in tariff sebesar USD\$0,25/kWh (Berdasarkan } \\
& \text { Peraturan Menteri ESDM Nomor } 17 \text { Tahun } 2013 \text { tentang } \\
& \text { Pembelian Tenaga Listrik Oleh PT Perusahaan Listrik } \\
& \text { Negara (Persero) dari Pembangkit Listrik Tenaga Surya } \\
& \text { Fotovoltaik. } \\
\text { - } \quad \text { Kurs dollar USD\$1 = Rp14.300,- }\end{array}$ \\
\hline & Pengurangan emisi $\mathrm{CO}_{2}$ & $\begin{array}{l}\text { - Faktor emisi } \mathrm{CO}_{2} \text { batubara sebesar 2,17 pound per } \mathrm{kWh} \text {. } \\
\text { - } \quad \text { iaya lingkungan akibat emisi CO2 sebesar USD } \$ 40 / \text { ton. }\end{array}$ \\
\hline
\end{tabular}

Kelayakan pembangunan PLTS pada Kabupaten Muara Enim ditentukan dari nilai NPV, IRR, ROI, dan profitability index. Hasil perhitungan biaya manfaat menunjukkan bahwa pembangunan PLTS pada Kabupaten Muara Enim layak untuk dilaksanakan, sebagaimana terlihat pada Tabel 4.

Tabel 4.

Analisa Kelayakan Pembangunan PLTS pada Kabupaten Muara Enim

\begin{tabular}{|c|l|c|l|}
\hline No & \multicolumn{1}{|c|}{ Uraian } & Hasil & \multicolumn{1}{c|}{ Keterangan } \\
\hline 1. & NPV & 1.253 .407 .310 .673 & \\
\hline 2. & IRR & $39,12 \%$ & $>$ tingkat suku bunga sebesar $13,5 \%$ \\
\hline 3. & ROI & $358,43 \%$ & $>0$ \\
\hline 4. & Profitability index & 2,776 & $>1$ \\
\hline
\end{tabular}

\section{Sensitivitas}

Salah satu tujuan analisis sensitivitas berdasarkan paparan dari Kementerian Keuangan yaitu untuk menilai apa yang akan terjadi dengan hasil analisis kelayakan kegiatan usaha jika ada perubahan pada perhitungan biaya/ manfaat. Sensitivitas atas pembangunan PLTS pada Kabupaten Muara Enim pada sisi biaya dilakukan atas prosentase kerusakan baterei per tahun dan kenaikan biaya operasional. Sedangkan pada sisi manfaat, sensitivitas dilakukan atas besaran tarif yang dikenakan oleh PT PLN (Persero) untuk pembelian listrik dan jam operasi dari PLTS.

Hasil analisis sensitivitas pada sisi biaya menunjukkan bahwa prosentase kerusakan baterei tidak mempengaruhi kelayakan dari pembangunan PLTS pada Kabupaten Muara Enim, dimana dengan prosentase kerusakan baterei sampai dengan 100\%, pembangunan PLTS tersebut masih layak. 
Vol. 1, No. 2, pp $78-85$

doi: $10.14710 /$ jebt.2020.11433

Sedangkan untuk biaya operasional, pembangunan PLTS menjadi tidak layak pada saat terjadi kenaikan biaya operasional sebesar 35\% per tahun. Hasil analisis sensitivitas pembangunan PLTS tergambar pada Gambar 4 dan Gambar 5.

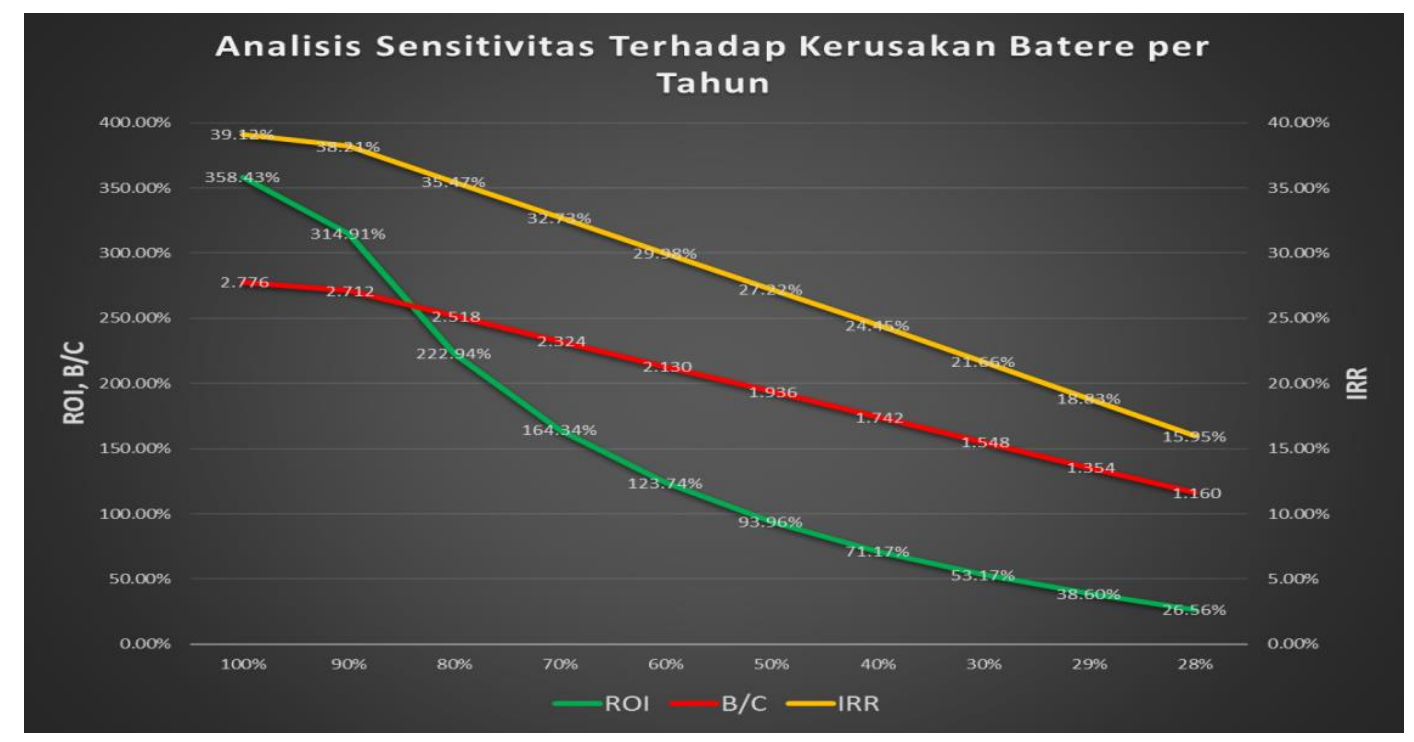

Gambar 4. Analisis Sensitivitas Terhadap Kerusakan Baterei Per Tahun

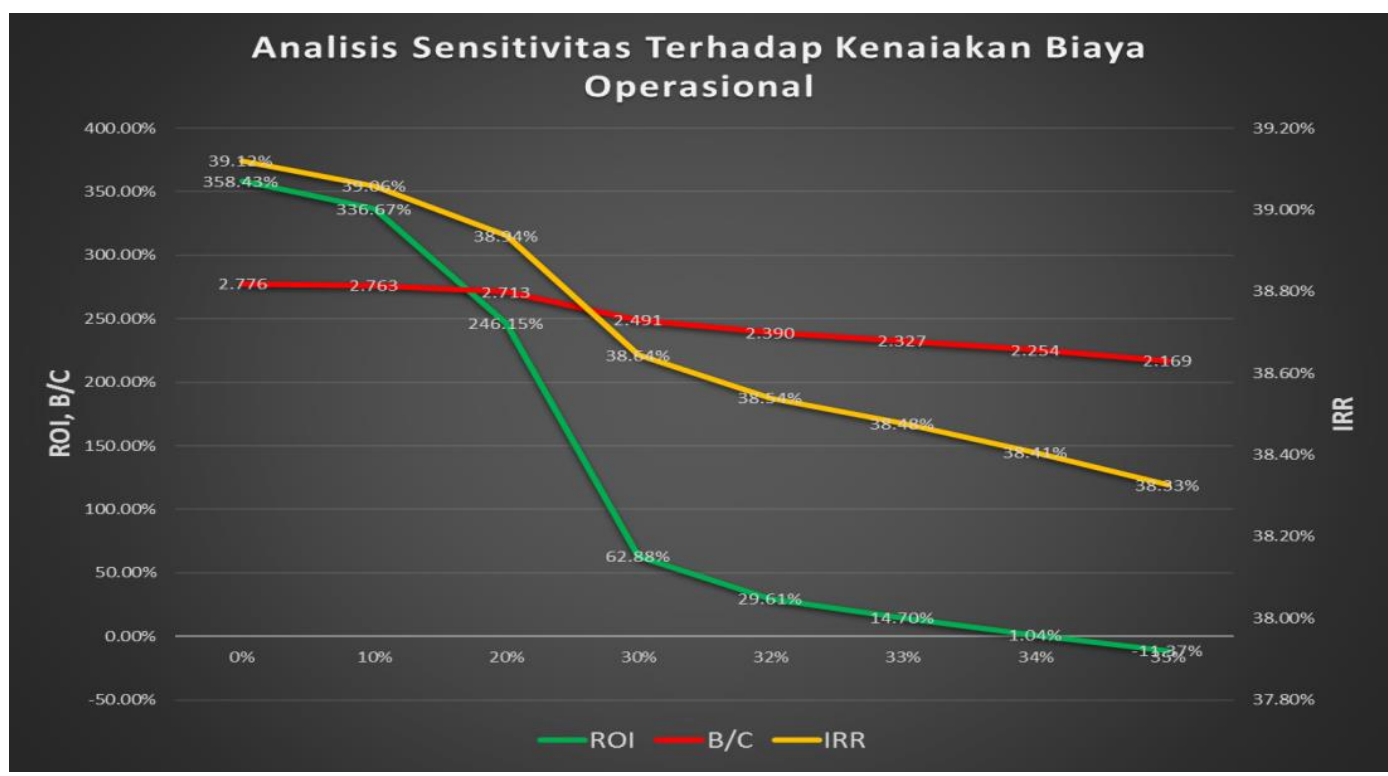

Gambar 5. Analisis Sensitivitas Terhadap Kenaikan Biaya Operasional

Hasil analisis sensitivitas pada sisi manfaat menunjukkan bahwa tarif yang dikenakan oleh PT PLN (Persero) mempengaruhi sensitivitas kelayakan pembangunan PLTS pada saat tarif untuk pembelian listrik ditetapkan sebesar $27 \%$ dari feed in tariff atau sebesar USD $\$ 0,07$. Sedangkan untuk jam operasi, pembangunan PLTS menjadi tidak layak pada saat jam operasi menjadi 3,7 jam per hari. Hasil analisis sensitivitas pembangunan PLTS tergambar pada Gambar 6 dan Gambar 7. 
Vol. 1, No. 2, pp $78-85$

doi: $10.14710 /$ jebt.2020.11433

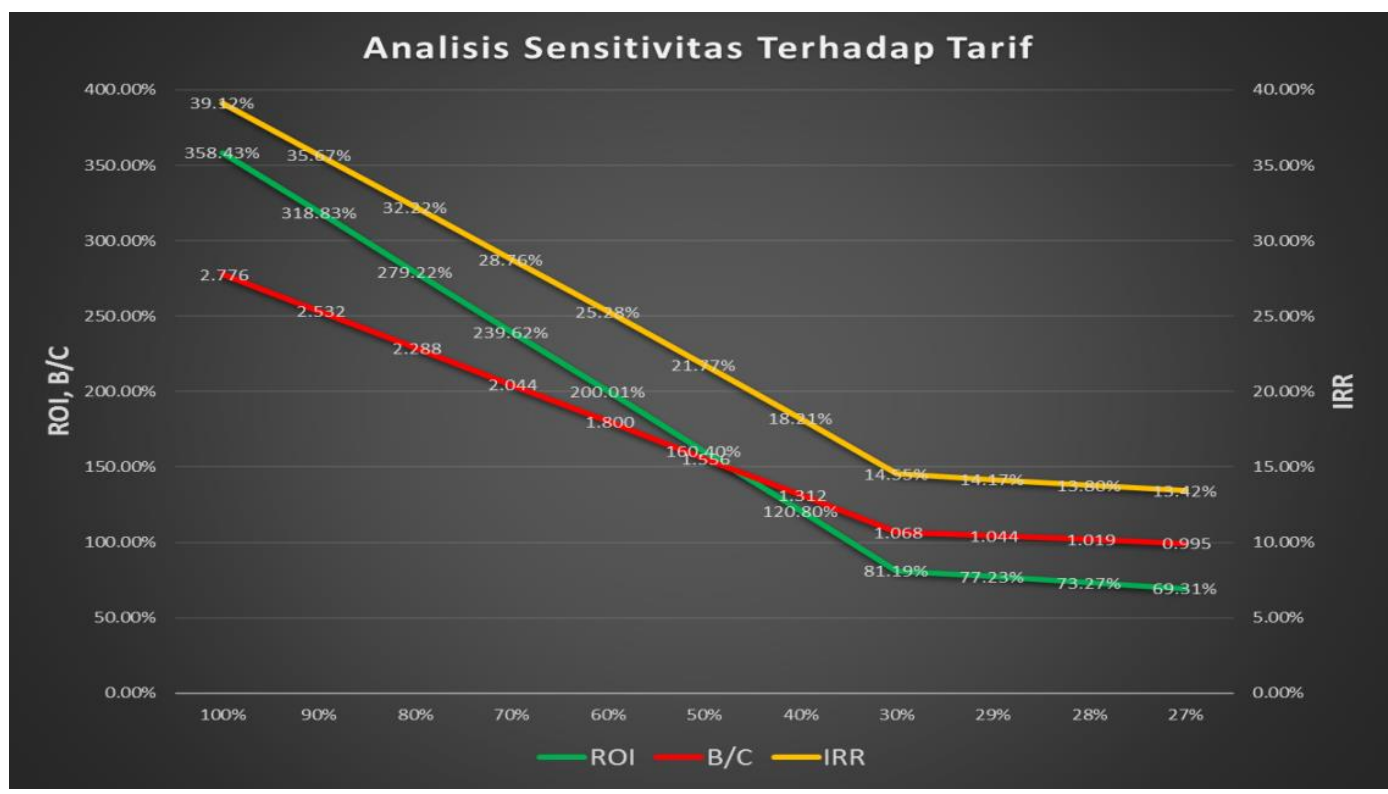

Gambar 6. Analisis Sensitivitas Terhadap Tarif

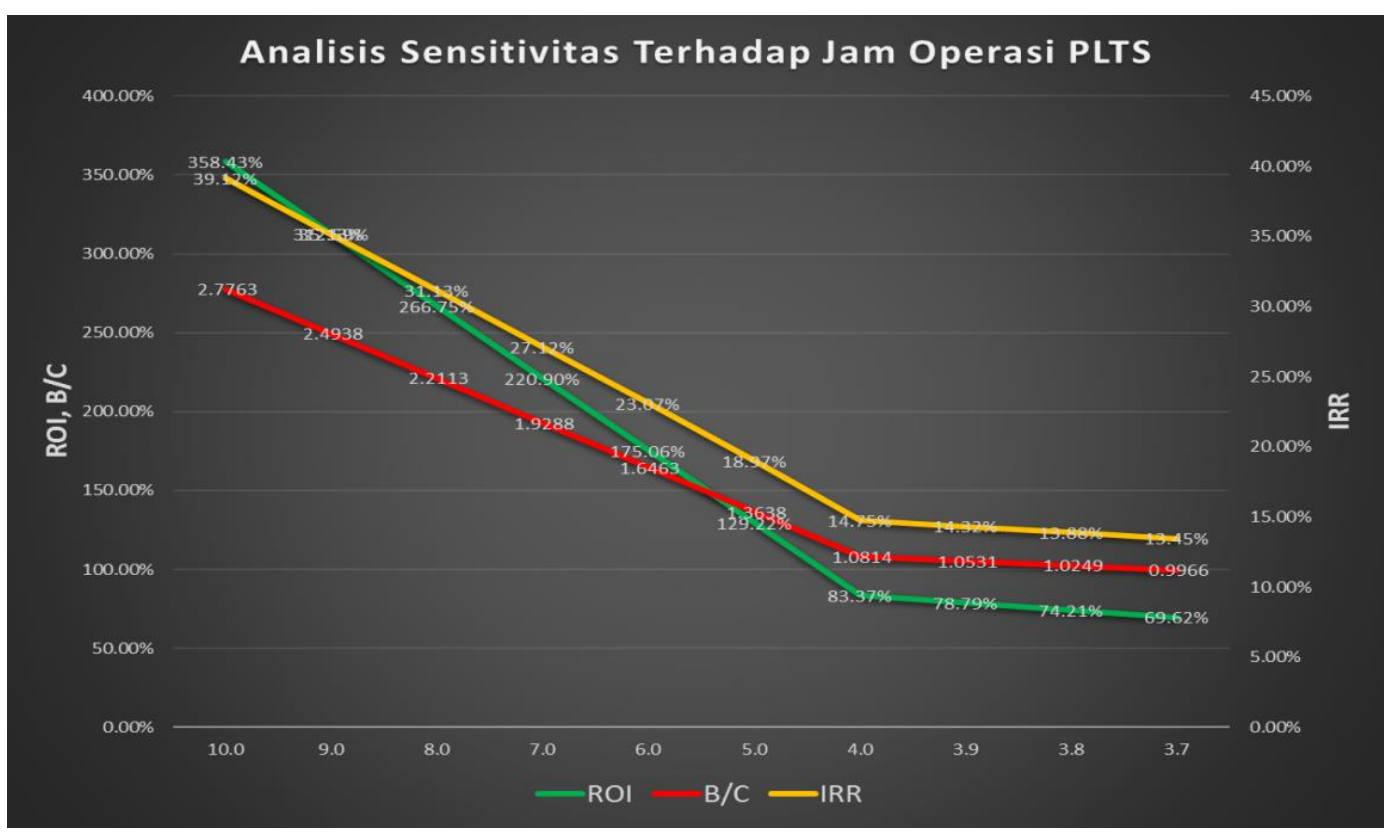

Gambar 7. Analisis Sensitivitas Terhadap Jam Operasi

\section{Kesimpulan}

Ketika tariff hanya dibayarkan sebesar 27\% maka proyek menjadi tidak layak. Persentase kerusakan batere per tahun tidak mempengaruhi kelayakan proyek PLTS. Proyek menjadi tidak layak ketika biaya operasional naik sebesar 35\% per tahun Proyek menjadi tidak layak ketika PLTS hanya beroperasi selama 3,7 jam.

Agar PLTS dapat berjalan dengan efektif, Pemerintah sebaiknya membayar tariff PLTS minimal sebesar 28\%. PLTS sebaiknya hanya dibangun ketika kenaikan harga operasional dibawah $35 \%$ per tahun. Pembangunan PLTS sebaiknya dilakukan di daerah yang minimal terkena cahaya matahari selama 3,8 jam. 
Vol. 1, No. 2, pp $78-85$

doi: $10.14710 /$ jebt.2020.11433

\section{Daftar Pustaka}

Outlook Energi Indonesia Pusat Pengkajian Industri Proses dan Energi (PPIPE) Badan Pengkajian dan Penerapan Teknologi (BPPT) 2020.

Internasional Energi Agency (IEA). (2021, Mei 4). World Energy Outlook 2020. Retrieved from Internasional Energi Agency (IEA): https://www.iea.org

Kementerian Energi dan Sumber Daya Mineral (KESDM). (2020). Ringkasan Renstra 2020-2024.

Jakarta: Kementerian Energi dan Sumber Daya Mineral.

Kementerian Energi dan Sumber Daya Mineral (KESDM). (2021, Mei 5). Kementerian Energi dan Sumber Daya Mineral. Retrieved from Direktorat Jenderal Energi Baru, Terbarukan dan Konservasi Energi: https://ebtke.esdm.go.id

Rencana Usaha Penyediaan Tenaga Listrik PT Perusahaan Listrik Negara (Persero) Tahun 2019 s.d 2028.

Peraturan Menteri Energi dan Sumber Daya Mineral Nomor 17 Tahun 2013 tentang Pembelian Tenaga Listrik Oleh PT Perusahaan Listrik Negara (Persero) dari Pembangkit Listrik Tenaga Surya Fotovoltaik.

Undang-Undang Nomor Nomor 16 Tahun 2014 tentang Pembentukan Kabupaten Buton Selatan di Provinsi Sulawesi Tenggara.

https://www.dunia-energi.com/akhir-2021-bukit-asam-mulai-proyek-plts-200-mw/

Kementerian Keuangan. Analisis Sensitivitas. Paparan.

Upah Minimum Provinsi Sumatera Selatan. Tahun 2020. Gubernur Sumatera Selatan.

Pusat Teknologi Pengembangan Sumber Daya Energi (PTPSE). (2015). Outlook Energi Indonesia 2015, Pengembangan Energi untuk Mendukung Pembangunan Berkelanjutan. Badan Pengkajian dan Penerapan Teknologi. Jakarta. 